\title{
Overview of Tuberculosis Coinfection with HIV in Ecuador 2010-2015
}

Ariel Torres ${ }^{1}$, María Cedeño ${ }^{2}$, Rosa Pinargote ${ }^{3}$, Martha Fors ${ }^{4}$

DOl. 10.21931/RB/2020.05.01.3

Abstract: To describe the behavior of Tuberculosis/Human Immunodeficiency Virus co-infection in a cohort of people affected by sensitive Tuberculosis in Ecuador from 01 January 2010 to 31 December 2015. Design: Secondary analysis and descriptive study of patients with TB/HIV in the study period. Results: The percentage of coinfected persons reached $11 \%$ in the whole period of study, with a range from $8.4 \%$ to $12.7 \%$. Male sex shows the highest incidence rate, representing $76.7 \%$ at the rate of 1 man for every 3.3 women. The population with the highest incidence of patients is economically active; the age group of 25-34 years reaches $40.1 \%$. The coastal zone of the country reports more than $75 \%$ of the coinfected patients. Conclusion: Increased HIV/AIDS screening should be increased for Tuberculosis, with particular emphasis on male sex and enhance the actions in the coastal provinces.

Key words: Tuberculosis, Human Immunodeficiency Virus, co-infection.

\section{Introduction}

Tuberculosis is one of the ten leading causes of mortality in the world. In 2015, 10.4 million people became ill with tuberculosis, and 1.8 million died from tuberculosis (including 0.4 million people with HIV). More than 95\% of tuberculosis deaths occur in low- and middle-income countries. It is estimated that one million children became ill of tuberculosis in 2015 and that 170,000 children died due to this cause (excluding children with HIV). Tuberculosis is one of the leading causes of death in HIV-positive people: by 2015, 35\% of HIV-related deaths were due to tuberculosis ${ }^{1}$. Global tuberculosis control faces significant challenges today. In general, intensive efforts are still needed to make quality care accessible to all, regardless of gender, age, type of illness, social environment and ability to pay. Co-infection with Mycobacterium tuberculosis and HIV (TB/HIV), especially in Africa, and multidrug-resistant (MR) tuberculosis, and extensively resistant in all regions, requires more complex and demanding control activity. Various risk groups require special attention. These challenges must be addressed by national tuberculosis programs with care tailored to each need. HIV is the main reason that tuberculosis control goals are not achieved in areas where HIV infection is prevalent. Tuberculosis, at the same time, is the most important cause of mortality among people living with HIV/AIDS? In 2015, 268,500 people with TB were estimated in the region of the Americas, with an incidence rate of $27.1 \times 100,000$, but 218,700 people with TB were notified, an incidence rate of $22.1 \times 100,000$, with a notification gap of 49,774 patients. Of the reported cases, 21,885 cases corresponded to TB/HIV Coinfection (9.49\%). 81.8\% of TB patients were aware of their HIV status, $12 \%$ of those who knew their HIV status were infected with HIV (TB/HIV). A total of 31,700 cases of TB associated with HIV were estimated; 6,000 people with HIV developed TB, of which $58.4 \%$ of patients with TB/HIV received Antiretroviral therapy (ART). The estimated number of deaths from TB was 18,500, of which 5,900 people died from TB/HIV 3 .

In 2015, the WHO estimate in Ecuador was 8,400 new cases of TB (51.6/100 a thousand inhabitants), including those with TB/HIV Coinfection, however, the National Health System
(NHS) diagnosed and reported 5,215 cases (32.03/100 a thousand inhabitants), and this represents $62.08 \%$ of the estimated, evidencing a gap between notification and estimation. In TB/HIV Coinfection, 545 cases were reported, representing $10.45 \%$ of TB cases, information obtained from the official database of the National Strategy for Tuberculosis Control and Prevention in Ecuador ${ }^{4}$. In 2014, the mortality rate reported by the National Institute of Statistics and Censuses (INEC) was 2.59 per ten thousand inhabitants.

\section{Materials and methods}

\section{Study population and methods}

A secondary analysis of the database of patients with sensitive tuberculosis and HIVinfected was performed. We included six years (2010-2015) in this analysis, and the total of patients reported during these years. The source of tables and figures was the Information System of the National Strategy for the Prevention and Control of Tuberculosis, collected by the Ministry of Public Health of Ecuador.

\section{Ethics approval and consent to participate}

The study did not need to be approved by the clinical research ethics committee since we worked with a de-identified dataset. We followed the STROBE checklist to report this work.

\section{Results}

The frequency of cases of sensitive TB, reflected in Figure 1, shows a progressive increment up to the year 2012, with a declination of the number of subjects with the disease in the last years. Similar behavior is evidenced in coinfected patients who maintain a rising curve until 2013, and from this year, a diminution of the number of cases with this condition.

\footnotetext{
${ }^{1}$ Specialist in Family Medicine. Master in Infectious Diseases. Ministry of PublicHealth, Ecuador.

${ }^{2}$ Doctor in Medicine and Surgery. Master in Epidemiology. Universidad Laica Eloy Alfaro, Manta, Manabí, Ecuador

${ }^{3}$ Nursing, Magister in Epidemiology. University of South Manabi.

${ }^{4}$ Doctor in Medicine. Specialist in Biostatistics. Master in Applied Statistics. Master in Pharmacology. Ph.D. in Medical Sciences. Universidad de Las Américas, Quito, Pichincha, Ecuador.
} 


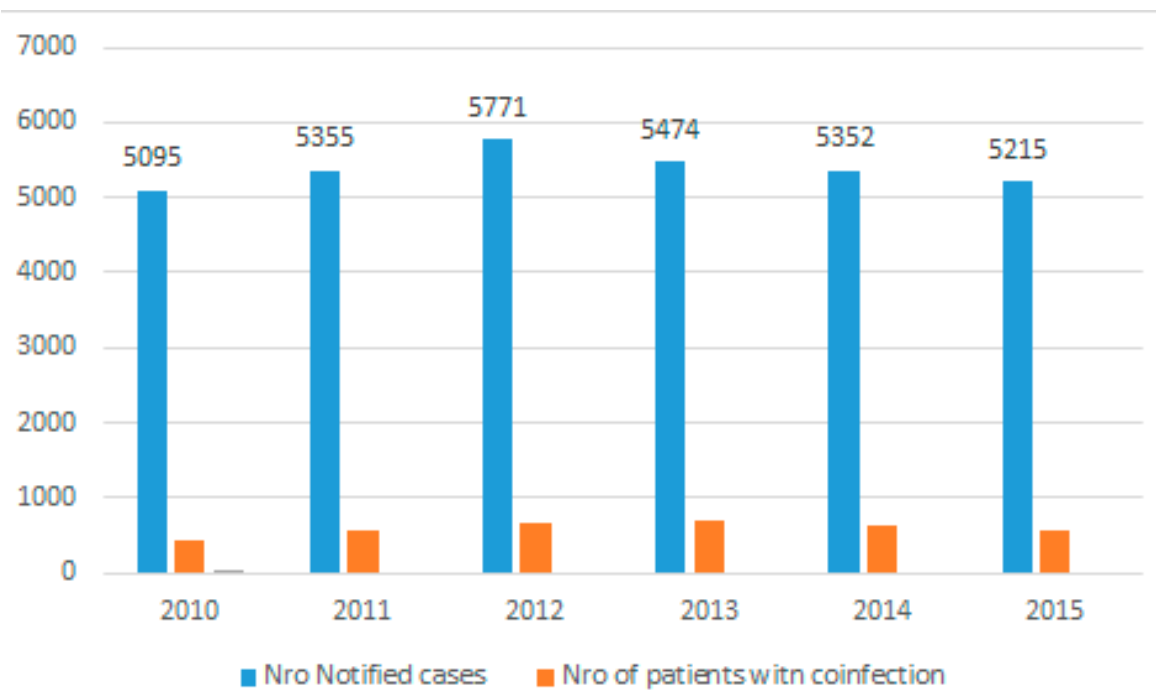

Figure 1. Incidence of cases of Tuberculosis and Co-infected TB/VIH, Ecuador 2010-2015.

Figure 2 shows the number and percentage of coinfected patients with sensitive TB. Ranges go between 8.4 and 12.7, being 2013 the year with the highest rate of coinfected cases. In the 6 years of study, coinfected represented $11 \%$ of the sensitive TB cohort.

During the six years (Figure 3 ), male sex was the most prevalent, with a percentage of 76.7 and at a rate of 3.3 men per woman. Men in economically active age represent the highest percentage of affected persons reaching more than
$80 \%$, the age group between $25-34$ reported the highest rate (41\%). With a frequency of 152 cases, the age group of $0-14$ years said $4.3 \%$

Ecuador has three main geographical areas: the mountainous area (sierra), the coastal zone and the amazonian region. Figure 4 shows the frequency of coinfected subjects by geographic area, the coastal zone with only four provinces of the country reports more than $75 \%$ of coinfection TB/ HIV.

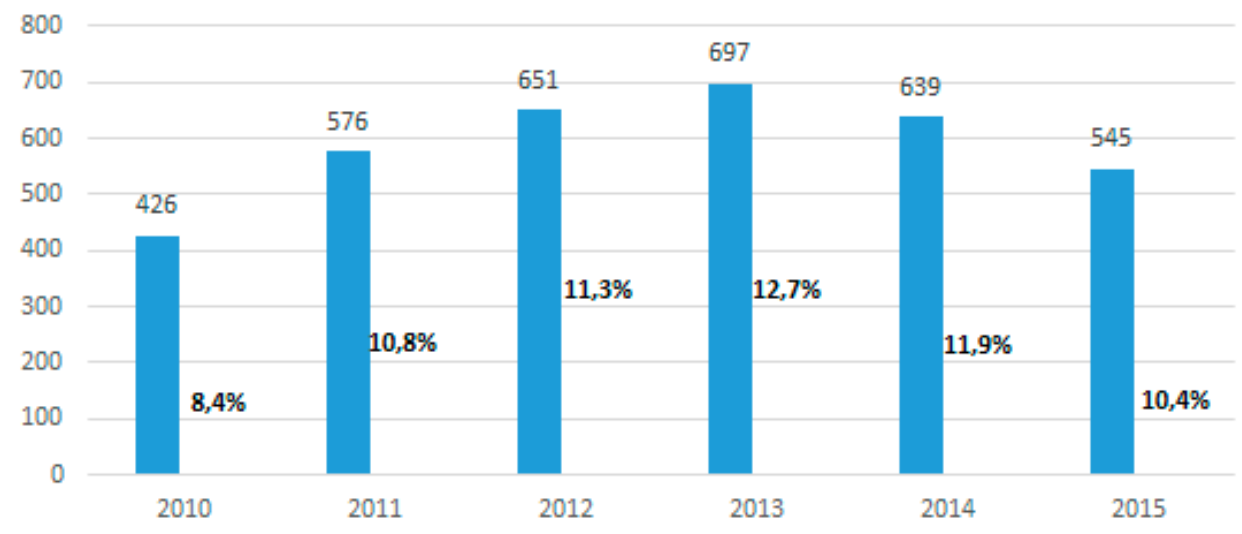

Figure 2. Frequency and percentage of cases with Coinfection in sensitive TB cohorts, Ecuador 2010-2015.

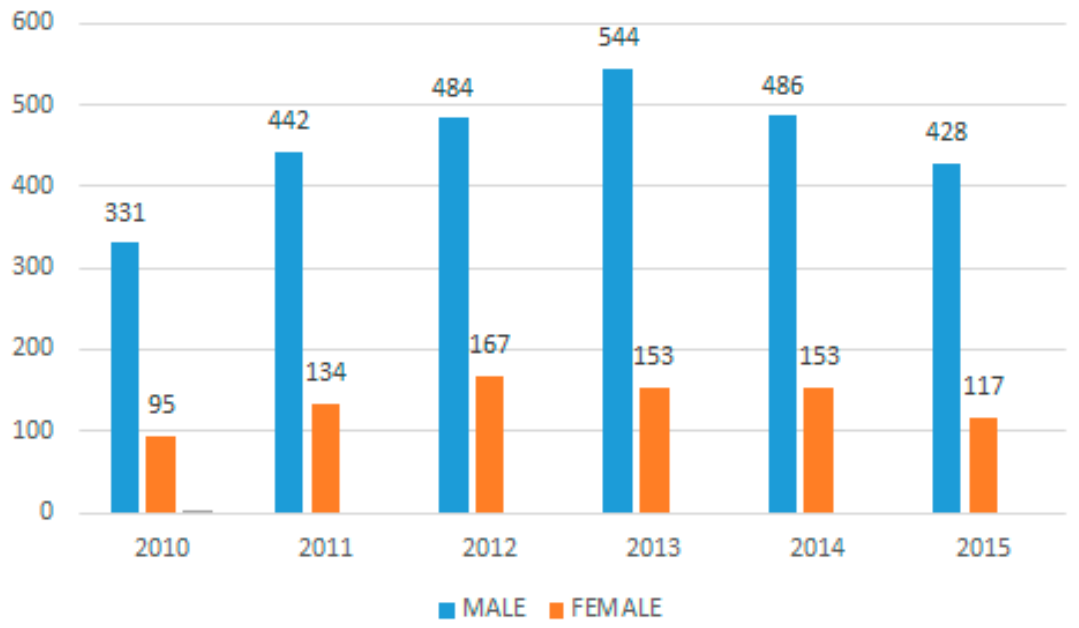

Figure 3. TB/VIH infection by sex, Ecuador 2010-2015. 
600

400

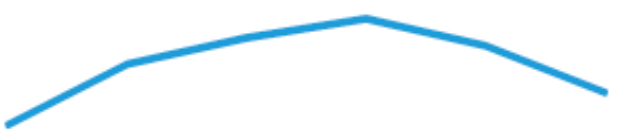

200

0

$\begin{array}{llllll}2010 & 2011 & 2012 & 2013 & 2014 & 2015\end{array}$

Figure 4. Number of cases according to geographical areas.

\section{Discussion}

The contribution of the Region of the Americas to the global burden of tuberculosis is only $4 \%$ of all forms of the disease. It is the second-largest region in the world and with the highest estimated incidence of TB/HIV coinfection. Estimates for 2009 showed around 24,000 cases of TB/HIV. This occurs in a region where significant progress has been made in the prevention and control of tuberculosis, as well as to access to antiretroviral treatment, and where in the same year was found that only $6 \%$ of the estimated cases of TB/HIV were reported. Undoubtedly, the lack of familiarity of clinicians with the manifestations of TB in the person with HIV, the diagnostic difficulties of both pulmonary and extrapulmonary forms, as well as the complexity of concomitant treatment contributes to unacceptable morbidity and mortality attributable to coinfection TB/HIV. This requires coordinated action for diagnosis, care and treatment. Collaboration between tuberculosis and HIV programs for the integration of care and treatment of both infections is a strategy that improves the diagnosis, treatment, and prognosis of patients with both diseases ${ }^{5}$.

Tuberculosis is the most common co-infection in HIV and the risk of presenting it in HIV-negative patients are 5-10\%; however, in those HIV-positive, the risk is 50\%. One-third of the increase in people with tuberculosis on the planet is attributed to the spread of HIV. One in three people who die from AIDS has TB, and $8-10 \%$ of all HIV-related deaths are TB-related. In some localities, tuberculosis is the cause of death for up to $50 \%$ of people with AIDS 6 .

In Ecuador, the frequency of cases of sensitive TB, as shown in Figure 1, does not show a progressive linear trend; nevertheless, a gradual increase is observed before 2012. Similar behavior is evidenced in coinfected patients who maintain an upward curve until 2013. In 2011, according to data from the World Health Organization (WHO), 8.7 million new cases of TB occurred, of which $13 \%$ were coinfected with HIV ${ }^{7}$. Ecuador shows coinfection rates very similar to those of the global trend. Countries in the region such as Peru had a $4.4 \%$ of coinfected cases with TB and HIV in 2014, and in 2006 a co-infection of less than $2 \%$ was reported, with screening coverage in patients who initiated primary anti-tuberculosis treatment tripled in the last 3 years, from a coverage of $20 \%$ for 2012 to a coverage of $73 \%^{8}$. According to data from the National Tuberculosis Control and Prevention Strategy in Ecuador, there is a progressive increase in HIV/AIDS screening for tuberculosis patients, starting in 2010 with $66 \%$ and by the end of 2015 reaching a screening rate above $90 \%$. The ratio between male and female ${ }^{9}$ ranged from 1.7 in 2005 to 2.3 in 2009 around the world. Despite the evident predominance of males in coinfected people, WHO/PAHO points out that TB has been a predominantly male disease.

Nowadays, due to the high rates of HIV infection in women, TB is more frequent in women than in men in many countries with high HIV prevalence, so the prevention, diagnosis, and appropriate treatment of TB in women is a priority. Because of the greater intimacy of contact, TB can spread more rapidly in families. Because women are often the caretakers of children, the sick, and the elderly, the fact that they can become ill with TB can have a double impact: on themselves and the most vulnerable members of the family because it reduces their ability to care for them ${ }^{10}$.

The average age of coinfected in a study in Colombia was 36.7 , the analysis in the six years of research in Ecuador, shows that the affected group aged 25-34 reported the highest percentage (41\%). Significantly, the population in the economically active age represents the highest percentage of affected people, reaching more than $80 \%$. The behavior of coinfection by geographical areas shows that the coast with only 4 provinces report more than $75 \%$ of TB/HIV coinfected subjects led by the region of Guayas with $60.8 \%$. A similar trend has this province in terms of rates of incidence and prevalence of cases of Sexual Transmitted Infections (STI) and HIV/AIDS according to data and reports issued by the National STI-HIV/AIDS Prevention and Control Strategy of Ecuador.

\section{Conclusions}

Although the country has shown significant progress in reducing tuberculosis mortality by more than $50 \%$, with a decreasing progressive curve, starting in 2006 with a rate of 5.77 and at the end of 2012, the rate reached 2.76; Tuberculosis continues to be one of the leading causes of mortality in patients with HIV/AIDS. It is important to note that another significant achievement of the country is to ensure that 100\% of coinfected people have started antiretroviral therapy, a factor that undoubtedly contributed to the reduction of the mortality rate.

\section{Acknowledgements}

The authors would like to thank the Ministry of Public Health of Ecuador (MSP) and Universidad de Las Américas for their support. 


\section{Consent for publication}

Not applicable.

\section{Data availability}

Data will be available on request at the National Strategy for Control and Prevention of Tuberculosis in the National Directorate of Prevention and Control Strategies of the Ministry of Public Health of Ecuador.

\section{Competing interest}

The authors declare that there are no competing interests.

\section{Funding}

\section{Authors contributions}

AT participated in the design of the study, collected data, interpreted the data, as well as drafted the manuscript. MC participated in the design of the study, collected data, and interpreted data. RP participated in the design of the study and collection of data. AT, MC, RP, MF made substantial contributions to conception and design and participated in the data collection. All authors reviewed and approved the final manuscript

\section{Bibliographic references}

1. World Health Organization. Tuberculosis. Available at: http:// www.who.int/mediacentre/factsheets/fs104/es/

2. World Health Organization. Tuberculosis y poblaciónes vulnerables: desafíos Available at: http://www.who.int/tb/challenges/es/

3. World Health Organization. Global Tuberculosis Report 2016. Switzerland; 2016. Available from: www.who.int/tb/publications/ global_report/en

4. Ministerio de Salud Pública. Prevención, diagnóstico, tratamiento y control de la Tuberculosis: Guía Práctica Clínica (GPC) Primera edición. Quito: Dirección Nacional de Normatización; 2015. Available at http://salud.gob.ec

5. Panamerican Health Organization. Coinfección TB/VIH: Guía Clínica Versión actualizada $2010 . \quad$ Available at: http://new. paho.org/hq/dmdocuments/2011/Coinfeccion_TB-VIH_Guia_Clinica_TB.pdf

6. Lozano JL, Plasencia C, Costa DM, Ventura S. Co-infection due to tuberculosis and human immunodeficiency virus: confluence of two epidemics. Available at: http://bvs.sld.cu/revistas/san/ vol_16_9_12/HTM/san15912.htm

7. World Health Organization. Global tuberculosis report 2014 [internet]. Geneva, Switzerland: WHO; 2014. Available at: http://www.who.int/tb/publications/global_report/en/index. html.

8. Ministerio de Salud Pública del Perú. Análisis epidemiológico de la Tuberculosis en Perú 2015. Available at: http://bvs.minsa.gob. pe/local/MINSA/3446.pdf

9. Saita NM, Oliveira HB. Tuberculosis, AIDS and tuberculosis-AIDS co-infection in a large city. Rev Lat Am Enfermagem. 2012;14:769-77. Available at: http://www.scielo.br/scielo.php?pid $=$ S010411692012000400018\&script=sci_arttext\&tlng=es

10. World Health Organization. Hablemos De Tuberculosis Y VIH. Available at: http://www.who.int/tb/challenges/hiv/talking_ points/es/index2.html

Received: 10 december 2019

Accepted: 30 january 2020 